\title{
ATTENTION AND PERSONALITY IN AUGMENTING/ REDUCING OF VISUAL EVOKED POTENTIALS
}

\author{
Georg Stenberg, ${ }^{1 \cdot *}$ INGmar Rosén ${ }^{1}$ and JARL RisberG ${ }^{2}$ \\ 'Department of Clinical Neurophysiology and ${ }^{2}$ Department of Psychiatry, University of Lund. \\ S-221 85 Lund, Sweden
}

(Received 9 March 1990)

\begin{abstract}
Summary-Earlier research has shown that extraverts tend to increase their visual evoked potential amplitudes with increasing light intensity (augmenting), while introverts reach their maximum amplitude at lower intensities (reducing). The evoked response has normally been measured from association areas of the brain (at the vertex). The present study measured VEP amplitudes over visual cortex and at the vertex, using four light intensities in two conditions, where attention was either directed towards the light stimuli, or away from them by a concurrent auditory task. Forty subjects were classified as extraverts or introverts based on the Eysenck Personality Inventory. The results show that attention interacted significantly with extraversion. Introverts exhibited a narrower focus of attention, while higher amplitudes and amplitude-intensity functions when attending to the light flashes and lower when distracted. Extraverts showed smaller differences between conditions, indicating a more evenly distributed attention. Higher arousal in introverts is the probable cause of their narrower focus of attention. There were marked differences in the distribution of activity between vertex and occipital cortex. Introverts showed relatively stronger occipital responses and extraverts stronger vertex responses across all intensities and in both conditions. The predisposition for mainly perceptual responses to aversive stimuli in introverts. and for general alerting and motor preparatory responses in extraverts, are interpreted as supportive of Brebner and Cooper's hypothesis that introverts are 'geared to inspect' and extraverts are 'geared to respond
\end{abstract}

\section{INTRODUCTION}

Individual differences in stimulus intensity control have been held to be important determinants of personality and temperament since the days of Pavlov. With the procedure devised by Buchsbaum and Silverman (1968), it seemed that these differences were amenable to direct, physiological measurement. The procedure, which records brain evoked potentials to light of different intensities, separates individuals on the basis of their amplitude-intensity functions. In some persons, termed augmenters, amplitudes increase with increasing intensity, whereas othersreducers-reach a point of saturation, beyond which amplitudes stagnate or decrease. The implication that the reducing pattern indicates protective inhibition, whereby sensitive nervous systems avert overstimulation, initiated extensive research efforts to link augmenting-reducing with important dimensions of individual differences. The search yielded a rich harvest, reviewed by Buchsbaum, Haier and Johnson (1983), of psychiatric and psychological phenomena with which augmenting-reducing covaried. In the field of personality psychology, it was found that individuals scoring high on measures of sensation seeking, and especially its subscale Disinhibition, were augmenters (Lukas, 1987; Stenberg, Rosén \& Risberg, 1988; von Knorring, 1980; Zuckerman, Murtaugh \& Siegel, 1974). Likewise, Eysenck's extraversion dimension correlated positively with augmenting (Friedman \& Meares, 1979; Soskis \& Shagass, 1974; Stenberg et al., 1988). The face validity of these findings, which linked sensation avoiding and introversion with the defensive reducing pattern, was further supported by observations in animal experiments, where augmenter cats exhibited more exploratory and fearless behaviour than reducers (Hall, Rappaport, Hopkins, Griffin \& Silverman, 1970; Lukas \& Siegel, 1977; Saxton, Siegel \& Lukas, 1987).

However, the opposite pattern has also been demonstrated, in a study (Haier, Robinson, Braden $\&$ Williams, 1984), where reducers scored higher on extraversion and sensation seeking. The range

\footnotetext{
*To whom all correspondence should be addressed.
} 
of stimulus intensities used has varied considerably between studies, and Lukas (1987) argues that the apparent conflict can be resolved by taking into account that only the highest intensities will provoke protective inhibition, and moderate intensities, such as the ones used by Haier et al., will tap a different type of amplitude-intensity function.

More disconcerting is the lack of consistency across sensory modalities. In theory, the principle of protective inhibition should apply to all modalities, but studies where both auditory and visual stimuli have been used have failed to find an intraindividual consistency in augmenting-reducing (Buchsbaum et al., 1983; Kaskey, Salzman, Klorman \& Pass, 1980; Raine, Mitchell \& Venables, 1981; Stenberg et al., 1988). Still, positive correlations between sensation seeking and auditory augmenting have been established (Como, Simons \& Zuckerman, 1984; Hegerl, Prochno, Ulrich \& Müller-Oelinghausen, 1989; Mullins \& Lukas, 1984; Orlebeke, Kok \& Zeillemaker, 1989), but the findings suggest that experimental parameters are of crucial importance. Thus, the relation with personality seems to obtain only when habituation is low (Hegerl et al., 1989), processing demands are high (Mullins \& Lukas, 1984; Orlebeke et al., 1989), and interstimulus intervals are short (Como et al., 1984).

Even for the visual EPs, questions of intraindividual consistency have been raised. An established tradition has measured augmenting/reducing in relation to a component (P90-N120) of the vertex response, thought to originate in non modality-specific areas of the brain. Measurements over the dedicatedly visual occipital cortex have, however, given a different picture. Some studies have found uniformly increasing amplitude-intensity functions (Lukas, 1987), and others have found an inverse relationship with the vertex response, to the effect that vertex augmenters tend to be occipital reducers and vice versa (Connolly \& Gruzelier, 1982; Dustman, Shearer \& Snyder, 1982; Stenberg et al., 1988). Augmenting-reducing theory cannot easily accommodate such findings, at least if it rests on the proposed mechanism of reticular arousal (Zuckerman et al., 1974), the effect of which would tend to operate indiscriminately over the cortex.

A further threat to the validity of the augmenting/reducing concept has been pointed out by Iacono, Gabbay and Lykken (1982). The problem of blinking and other eye muscle artifacts has been underestimated in the augmenting/reducing literature. In fact, myogenic activity originating in the eye region is very common in VEPs, even with the best stimulus control, such as a Maxwellian view apparatus (Allison, Matsumiya \& Goff, 1977), and the problem is exacerbated by high stimulus intensities. As argued by Iacono et al, activity in this area will tend to interfere through volume conduction with recorded vertex activity. Positive-going EOG deflections may cancel or detract from the negative peak, N120, which is the major determinant of augmenting-reducing, and misleadingly create the impression of diminished neural activity. The reducing phenomenon could be an artifact or more frequent blinking at higher intensities, and the purported relationship between neural inhibition and personality would then degrade to one between blinking rates and personality.

Finally, the aspect of attention has often been neglected. The augmenting-reducing paradigm generally makes few restrictions on the psychological state of the subject, since instructions typically are just to watch the flashes. However, it is well established that the vertex N120 is sensitive to the effects of attention (Hillyard, Picton \& Regan, 1978; Näätänen \& Picton, 1987), and the possible interactions between attention, stimulus intensity and personality are impossible to predict from theory alone. Only one study of visual augmenting-reducing has varied the level of attention to the stimuli (Schechter \& Buchsbaum, 1973), and it did not include any measure of personality. Among its findings was that heightened attention tended to increase amplitudes more at the low intensities than at the high ones, thereby flattening the amplitude-intensity slopes and diminishing the interindividual variability.

The purpose of the present study is, first, to vary the level of attention in the augmenting/reducing paradigm in order to explore the possibility that attention mediates the relation between personality and the amplitude-intensity function. Second, by recording and controlling for EOG activity, the contribution of myogenic potentials to the vertex response will be examined. Third, the vertex response, the occipital response and the relation of each to personality variables will be compared. As regards personality, the main focus will be on extraversion (defined by the Eysenck Personality Inventory), but results for the Sensation Seeking subscale Disinhibition will also be discussed. 


\section{METHODS}

\section{Subjects}

Forty-one psychology and medical students volunteered and were paid for their participation. Data from one $S$ were were discarded due to episodes of drowsiness and persistent artifacts. Of the remaining $40 S \mathrm{~s}, 30$ were female. Ages ranged from 19 to 35 , with a median of 23.5.

\section{Personality measurement}

The $S$ s completed Swedish translations of the Eysenck Personality Inventory, form A (Eysenck \& Eysenck, 1969), and the Sensation Seeking Scale, form IV (Zuckerman, 1979), at home before the experimental session. The Extraversion score from the EPI and the Disinhibition score from the SSS were used in subsequent analyses.

\section{Procedure}

EP recording at four light intensities were made under two conditions: Attend, where $S$ s were asked to count the number of flashes silently, and Ignore, where the instruction was to watch the flashes while listening to a tape recorded lecture, with the understanding that a test on the contents of the lecture would be taken after the session. In both conditions, instructions emphasized that the gaze be fixated on the center of the screen, and that blinks should be avoided immediately following a flash. Stimuli of the same intensity were given in a block of 2-3 min, with rest periods of approximately the same duration between blocks. The order of the conditions and of intensity blocks within conditions were counterbalanced by randomization.

Recordings were made in a darkened room, where the $S$ sat comfortably in a slightly reclining chair with a head rest. Flash stimuli were produced by a Siemens photostimulator and viewed by the $S$ through a translucent screen, $30 \times 45 \mathrm{~cm}$, at a distance of $110 \mathrm{~cm}$. Four intensities were used, having luminances of $39,79,175$ and $295 \mathrm{~cd} / \mathrm{m}^{2}$, measured on $40 \mathrm{~Hz}$ intermittent light. Flashes had a duration of $40 \mu \mathrm{sec}$. (Thus, peak intensities were underestimated in the measurement procedure by approximately a factor of 625 , i.e. $1,000,000 / 1600$.) The four intensities used were identical to the four highest intensities in Stenberg et al. (1988).

Each stimulus was repeated with an interstimulus interval randomized around $2 \mathrm{sec}$, until 64 artifact-free sweeps had been obtained. The rejection rate was typically around $10 \%$, in some individuals running up to $40 \%$.

\section{Data acquisition}

EEG derivations were made from four positions along the midline: $\mathrm{Fz}, \mathrm{Cz}, \mathrm{Pz}$ and $\mathrm{Oz}$, all referred to the left earlobe, the forehead being connected to ground. In addition, one channel was used to monitor blinks and eye movement; this recorded the voltage between one electrode above the ridge of the right eye and another beside the outer canthus of the left eye (Connolly \& Kleinman, 1978). Before the EP procedure began, the $S$ was asked to blink repeatedly, and the automatic artifact rejection level was adjusted according to the EOG channel amplitude, so that all sweeps with blinks or eye movements having equal or higher amplitude would be rejected.

All electrode impedances were kept below $10 \mathrm{k} \Omega$. The filter pass band was $0.5-70 \mathrm{~Hz}$. Three hundred msec before the stimulus and $700 \mathrm{msec}$ after it was digitized at a sampling rate of $512 \mathrm{~Hz}$, and averaged EPs were stored on disk.

\section{Data processing}

The prestimulus epoch was averaged to form a baseline for each EP, which was subtracted from all post-stimulus data points. The $\mathrm{Cz}$ and $\mathrm{Oz}$ channels were scored for peak amplitudes and latencies by a cursor-controlled computer program. Care was taken to ensure that the same component was measured at all intensities.

Statistical analyses are largely based on repeated measures ANOVAs. Since falsely significant results may emerge if Fs based on pooled variances are uncritically used (Vasey \& Thayer, 1987), only single-degree-of-freedom linear trend contrasts will be used here. 


\section{RESULTS}

\section{Personality}

The group averages for both extraversion $(13.3 \pm 5.3)$ and neuroticism $(9.2 \pm 4.9)$ were slightly higher than those of the Swedish standardization group for the EPI (12.3 and 7.6, respectively). Average Disinhibition score was 5.8 (SD 3.1) There was a 0.54 correlation between Extraversion and Disinhibition.

For the purpose of ANOVAs, the distributions of Extraversion and Disinhibition were split at the median to provide a high and a low group for each variable. There was no significant difference in sex distribution between either the Extraversion groups $\left[\chi^{2}(1)=2.13\right]$ or the Disinhibition groups $\left[\chi^{2}(1)=0.53\right]$. There were no age differences between Extraversion groups, but there was a non-significant tendency for High Disinhibitors to be younger $[F(1,38)=2.96 ; P=0.094]$. Eight $S$ s were classified differently by the Extraversion and Disinhibition median splits: four introverts were high disinhibitors, and four extraverts were low disinhibitors.

Considering the high covariation between Extraversion and Disinhibition, only results for Extraversion will be given for most analyses, and results for Disinhibition will be discussed only when they lead to different conclusions.

\section{Grand average curves}

Figure 1 shows grand average curves, collapsed across $S$ s and stimulus intensities, for the five derivations and the two conditions. Effects of attention are notable in the frontal and central derivations, where the N120-P200 complex is enhanced; in the posterior leads where late positivities are deepened; and in the EOG, where artifacts are reduced. The EOG channel shows its main deflection in the $100-150 \mathrm{msec}$ latency range, with a peak around $130 \mathrm{msec}$, probably identical to the myogenic P130 identified by Allison et al. (1977). The strategy of individually adjusted automatic artifact rejection proved successful in eliminating most of the later (latency around $200 \mathrm{msec}$ or more) and larger potentials usually associated with blinking, but the record also shows that myogenic activity of a not negligible amount passes detection, and rejection, by such a procedure.
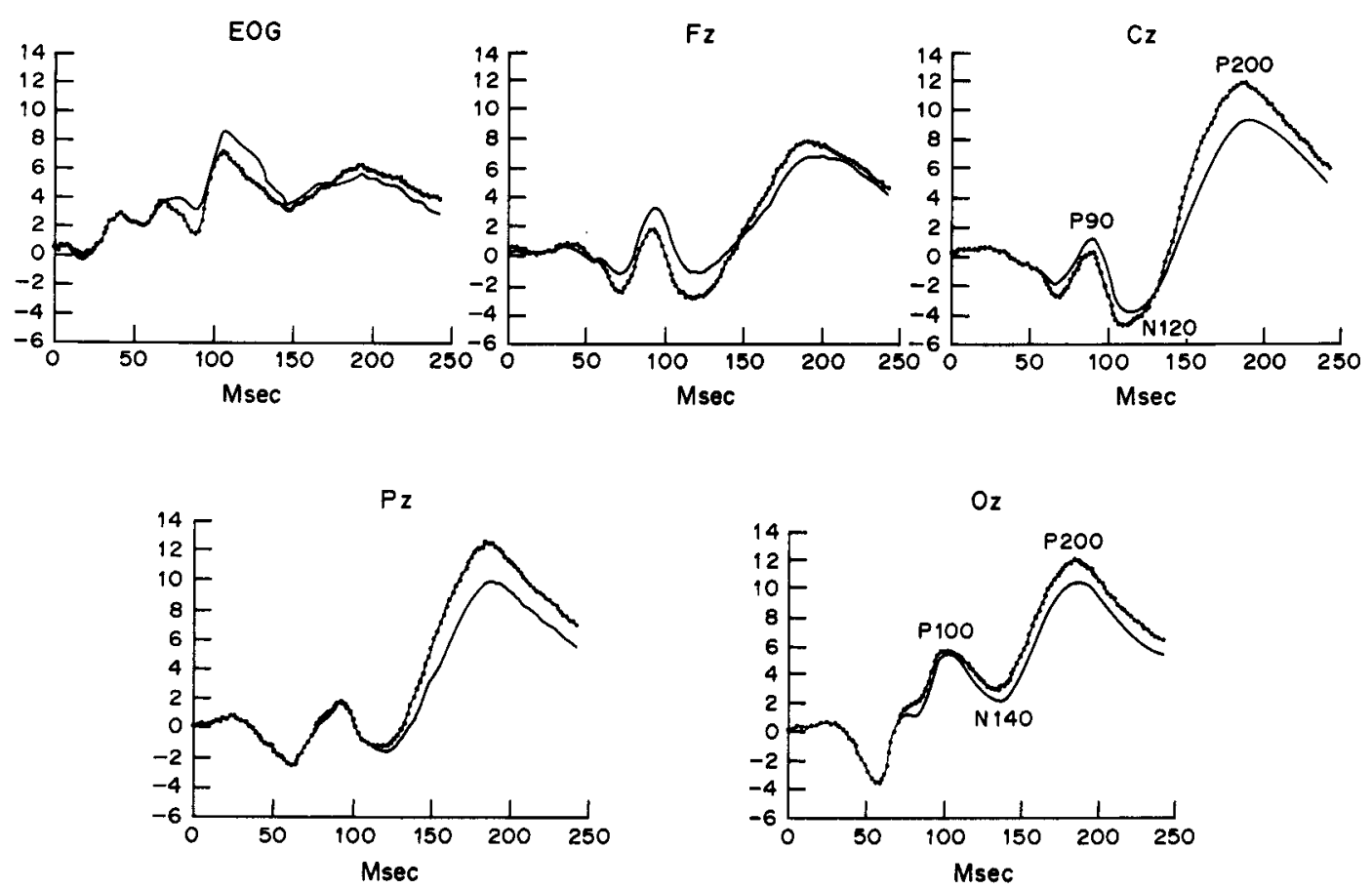

Fig. 1. Mean curves, averaged over stimulus intensities and $S \mathrm{~s}$, showing evoked responses in the Attend (dotted line) and Ignore (solid line) conditions. 
Table I. Correlations between amplitude/intensity slopes and personality variables

\begin{tabular}{llcc}
\hline & & Extraversion & Disinhibition \\
\hline Cz: P90-N120 & Attend & 0.04 & -0.03 \\
& Ignore & 0.16 & 0.11 \\
Cz: N120-P200 & Attend & -0.13 & -0.05 \\
& Ignore & 0.25 & 0.15 \\
Oz: N60-P100 & Attend & -0.13 & -0.04 \\
& Ignore & -0.29 & $-0.35^{*}$ \\
Oz: P100-N150 & Attend & $-0.31^{*}$ & -0.29 \\
& Ignore & $-0.3 ! *$ & $-0.36^{*}$ \\
\hline
\end{tabular}

$P<0.05$

\section{Peak-to-peak slopes}

Correlations between personality and measures of augmenting-reducing as conventionally defined, i.e. slopes of the linear regression function relating peak-to-peak amplitudes to (log) stimulus intensity, are given in Table 1 . The most commonly used measure, the slope of the vertex P90-N120, showed no significant relation to personality variables. However, several significant negative correlations between occipital activity and extraversion or disinhibition emerged.

Earlier results have shown that peak-to-peak measures often confound the contributions made by adjacent components which may react differently to the experimental conditions (Connolly \& Gruzelier, 1982). Furthermore, slopes often describe the relation between amplitude and intensity poorly (Connolly \& Gruzelier, 1982; Iacono et al., 1982). The following analyses will therefore focus on peak-to-baseline amplitudes of the major components.

\section{Peak amplitudes}

Vertex. Three components were measured in the $\mathrm{Cz}$ recording: $\mathrm{P} 90$ (latency, mean $\pm \mathrm{SD}: 91 \pm 7$ ), N120 (118 \pm 11$)$ and P200 (197 \pm 20$)$. Amplitude values were subjected to 3-way ANOVAs using a 2 (Extraversion groups) $\times 2$ (Attention levels) $\times 4$ (stimulus intensities) model with repeated measures on the last two factors.

All components showed effects of attention; for P90: $F=8.00 ; P=0.007$; for N120: $F=16.80$; $P=0.0002$ : and for P200: $F=26.59 ; P=0.00001$. (All $F$-values here and in the following, unless otherwise stated, are associated with 1,38 degrees of freedom.) However, while both N120 and P200 were enhanced by attention, P90 was diminished. Figure 1 shows that a processing negativity (Näätänen \& Picton, 1987) operates over a latency range from 70 to $140 \mathrm{msec}$, displacing all components in this range in the negative direction.

Increasing stimulus intensity increased the amplitudes of both $\mathrm{P} 90(F=13.93 ; P=0.001)$ and P200 $(F=11.10 ; P=0.002)$, but it had no effect on $\mathrm{N} 120(F<1)$. There were no significant Attention $\times$ Intensity interactions across groups.

For the N120, extraversion groups had their amplitude-intensity functions differentially affected by the Attention instructions (Extraversion $\times$ Attention $\times$ Intensity interaction: $F=4.76$; $P=0.035$ ). Figure 2 illustrates this relationship. Introverts augmented more than extraverts in the Attend condition and reduced more in the Ignore condition. The pattern in the Ignore condition conforms to earlier findings in the augmenting-reducing literature, with extraverts displaying an increasing tendency over intensities, and introverts showing decreases. The pattern is reversed in the Attend condition, where amplitudes are higher overall, and reach a maximum at intermediate intensities, earlier for extraverts than for introverts.

The P200 shows a similar effect (Extraversion $\times$ Attention $\times$ Intensity interaction $F=6.88$; $P=0.012$ ). Although superimposed on a stronger main intensity effect, the relation between personality groups repeats itself from the N120 (Fig. 3). In the Ignore condition, the expected pattern of steep increases among extraverts and levelling-off among introverts is obtained. In the Attend condition, the relationship is reversed, with introverts showing the steepest increases. The difference in the way the personality groups reacted to the instructions also resulted in a marginally significant Extraversion $\times$ Attention interaction: $F=3.95 ; P=0.054$.

Occiput. Three components in the $\mathrm{Oz}$ response will be reported here: P100 (latency $104 \pm 12$ ), N140 (latency $138 \pm 13$ ) and P200 (latency $189 \pm 15$ ). An earlier component, N60 showed no effects of attention, intensity or personality. 


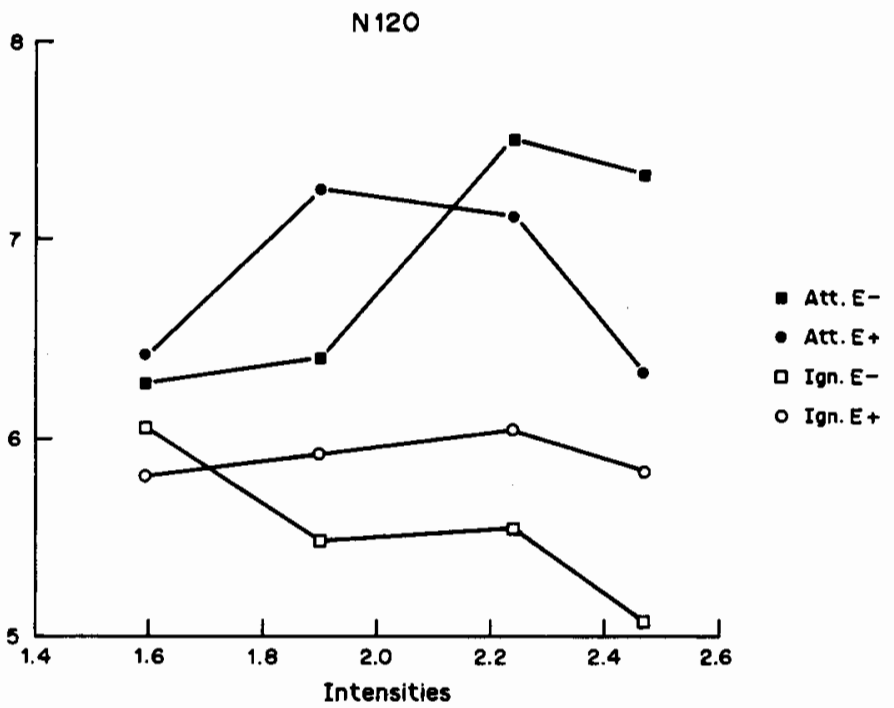

Fig. 2. Vertex N120 amplitudes for extraverts $(E+)$ and introverts $(E-)$ in the Attend (Att.) and Ignore (Ign.) conditions. Abscissa is log stimulus intensities.

All three components were affected by attention, although not as strongly as the vertex peaks: P100: $F=12.56 ; P=0.001 ; \mathrm{N} 140: F=7.48 ; P=0.009$; and P200: $F=12.60 ; P=0.001$. The positive components were enhanced, and the negative one was diminished, as is apparent in Fig. 1.

Intensity effects were significant for the two later components; N140: $F=14.52 ; P=0.0005$; and P200: $F=8.49 ; P=0.006$. The negative component decreased, and the positive increased, with higher intensities, i.e. the later part of the curve was pushed toward more positive voltages by increasing intensity.

A significant Extraversion $\times$ Intensity effect, illustrated in Fig. 4, emerged for the N140 component: $F=4.17 ; P=0.048$. The reducing of the $\mathrm{N} 140$ amplitude across intensities is markedly steeper in extraverts than in introverts, and this holds for both Attention conditions.

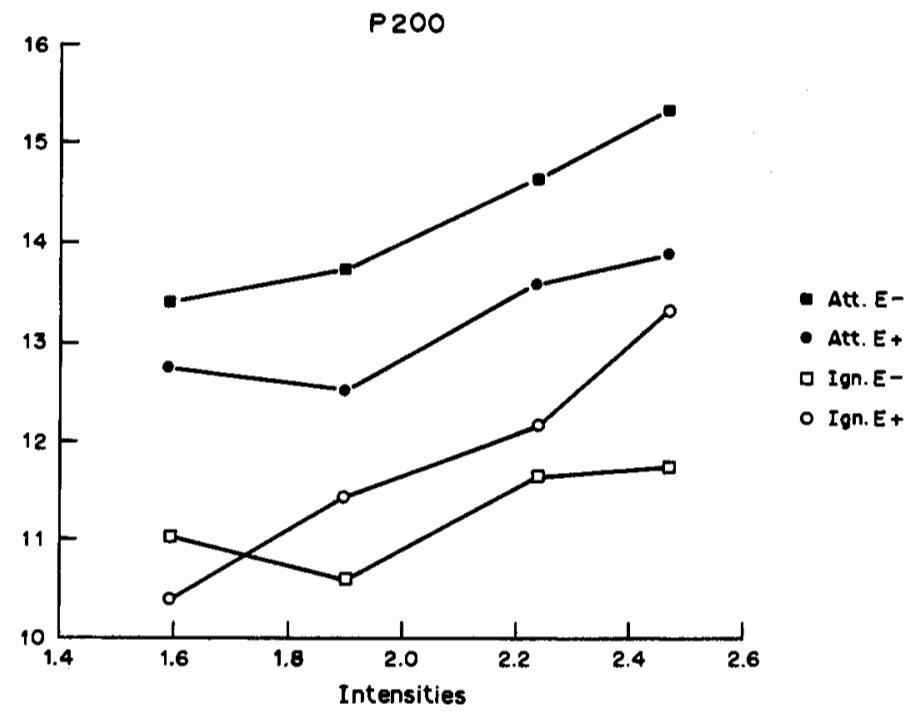

Fig. 3. Vertex P200 amplitudes for extraverts and introverts in the Attend and Ignore conditions. Abscissa is $\log$ stimulus intensities. 


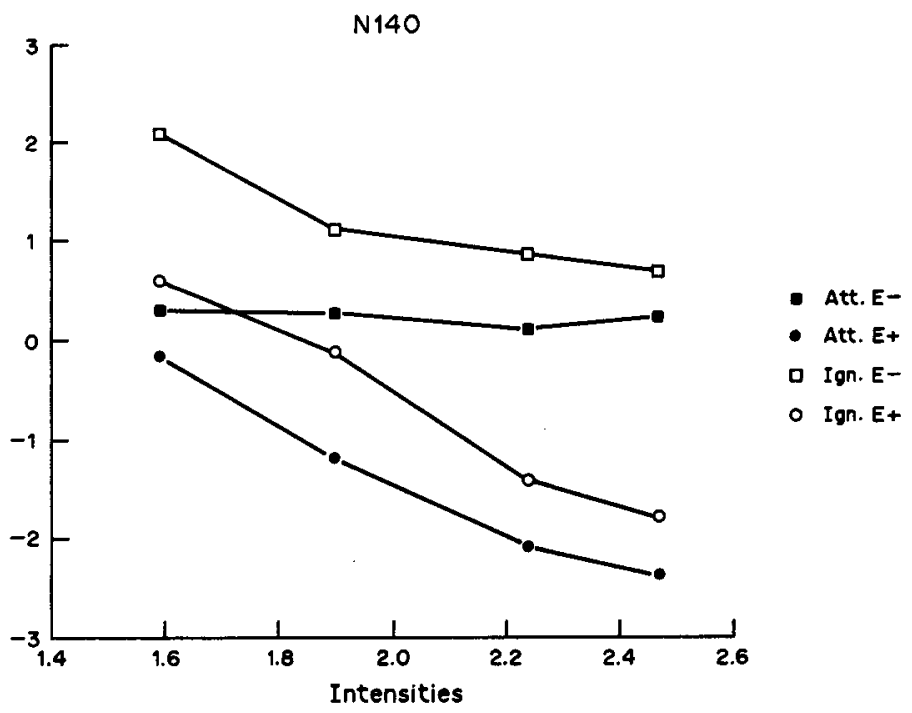

Fig. 4. Occipital N140 amplitudes for extraverts and introverts in the Attend and Ignore conditions.

Disinhibition. The tendency of the results were the same for Disinhibition as for Extraversion. The three-way interaction for the vertex $\mathrm{N} 120$ was equal in size and direction $F=4.78 ; P=0.035$ ), but the Disinhibition effects on P200 were not significant.

For the occipital N140, the Disinhibition $\times$ Intensity interaction was stronger $(F=9.46$; $P=0.004)$ than that involving Extraversion. A similar Disinhibition $\times$ Intensity effect was also obtained for the P100, with an augmenting tendency for low Disinhibitors, and a reducing tendency for high Disinhibitors $(F=4.33 ; P=0.044)$.

\section{Myogenic activity}

Since the artifact rejection procedure had not proved successful in removing all of the EOG, measures of EOG activity were obtained by calculating average amplitude in the $100-150 \mathrm{msec}$ and the 150-250 msec latency bands (Fig. 1). If the objections of Iacono et al. (1982) were justified, the early EOG activity would correlate negatively with the vertex N120 amplitude, since positive voltages in this latency range would detract from the size of the N120 component. This proved indeed to be the case. The correlation was -0.44 , calculated over all 320 measurements, and highly significant. A regression function indicated that each $1 \mu \mathrm{V}$ increase in EOG amplitude detracted $0.25 \mu \mathrm{V}$ from the N120 peak. Therefore, the N120 amplitudes were regressed on EOG activity, and the residuals were saved and subjected to new ANOVAs. Removal of all influence of the EOG did not alter any conclusions concerning the N120. The effect of Attention was somewhat reduced but went in the same direction $(F=8.55 ; P=0.006)$, and the Extraversion $\times$ Attention $\times$ Intensity interaction was markedly enhanced $(F=10.06 ; P=0.003)$. Inspection of group averages showed that in the Ignore condition, extraverts were relative augmenters and introverts were reducers, while in the Attend condition, introverts were augmenters and extraverts showed no clear linear trend (Fig. 5). Similar results were obtained for Disinhibition.

Analysis of the early EOG mean amplitudes themselves showed that they increased linearly with intensity, but also that they showed an Extraversion $\times$ Attention $\times$ Intensity interaction $(F=5.33$; $P=0.026$ ). This was caused by the fact that extraverts showed particularly high myogenic activity at the high intensities in the Ignore condition.

Regressing P200 on late (150-250) EOG and analyzing the residuals did not alter any conclusions about significant effects on this component: Attention: $F=30.34 ; P=0.000003$; Intensity: $F=8.34 ; P=0.006$; Extraversion $\times$ Attention: $F=4.03 ; P=0.052$, and Extraversion $\times$ Attention $\times$ Intensity: $F=5.31 ; P=0.027$.

\section{Topographic distribution of activity}

In view of earlier findings of an inverse relationship between specific $(\mathrm{Oz})$ and non-specific $(\mathrm{Cz})$ 


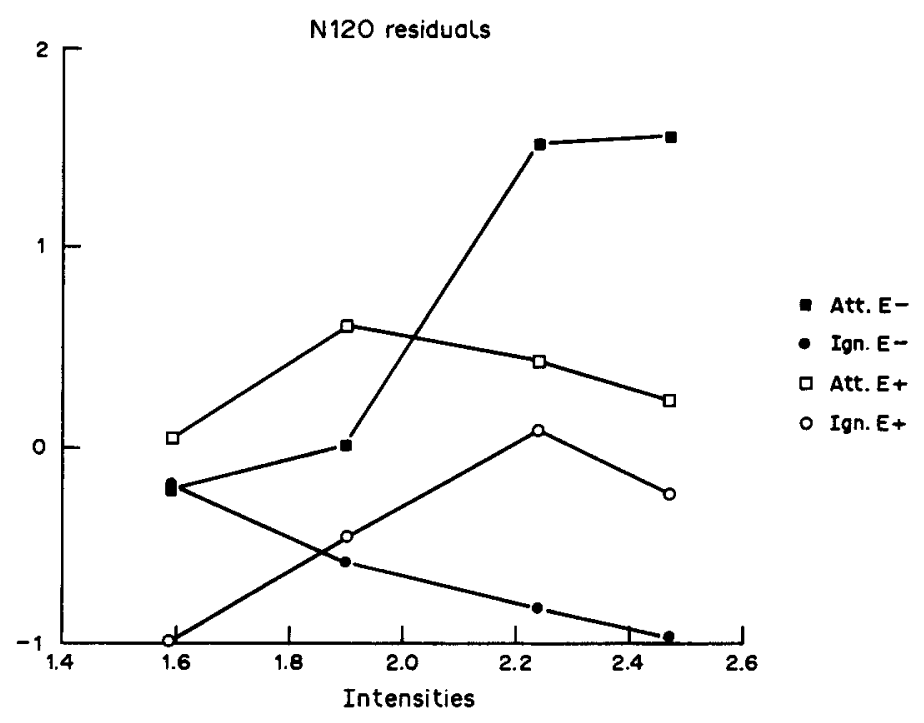

Fig. 5. Residuals of vertex N120 amplitudes after regression on EOG amplitude for extraverts and introverts in the Attend and Ignore conditions. The intercept of the regression function was $7.6 \mu \mathrm{V}$.

activity, it was deemed desirable to derive a measure of overall activity in the crucial time band 90-150 msec, which could be compared between electrodes. Peak amplitudes, since they refer to different latencies in different locations, are not strictly comparable. Instead, standard deviations of the voltage samples within the time band (Cohn, Dustman \& Shearer, 1985; Soskis \& Shagass, 1974) offered itself as a suitable quantity, which correlated well with the peak amplitudes that fell within the time band (e.g. $r=0.65$ between vertex SD and P90-N120 peak-to-peak amplitude, and $r=0.55$ between occipital SD and P100-N140 amplitude). An index of the balance between the standard deviations at $\mathrm{Cz}$ and $\mathrm{Oz}$ was computed as $(\mathrm{Cz}-\mathrm{Oz}) /(\mathrm{Cz}+\mathrm{Oz})$.

The index was calculated for each measurement, and the resulting data set was subjected to repeated measures ANOVAs. The results showed a main effect of extraversion $(F=4.83$; $P=0.034$ ), caused by more negative values, i.e. more relative occipital activation, for introverts in both conditions and at all intensities (Fig. 6). There was also a significant effect of Attention $(F=4.97 ; P=0.032)$, indicating more positive values, i.e. more vertex activation, in the Attend condition. The linear intensity effect $(F=3.14 ; P=0.085)$ failed to reach significance, but indicated a tendency toward more positive values with higher intensities.

Disinhibition did not exert a main effect, but the Disinhibition $\times$ Intensity $(F=8.75 ; P=0.005)$ and the Disinhibition $\times$ Attention $\times$ Intensity $(F=6.78 ; P=0.013)$ interactions were both significant. Group averages, illustrated in the right half of Fig. 6, show that high Disinhibitors had more positive values than low Disinhibitors, that the difference increased with higher stimulus intensities, and that this was especially the case in the Ignore condition.
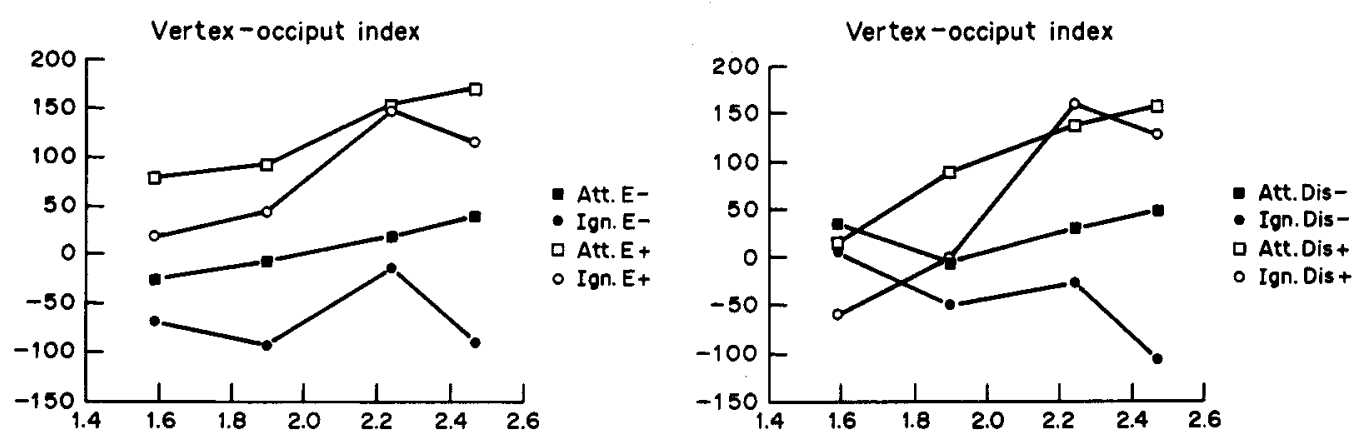

Fig. 6. SD-index (multiplied by 100) of the balance between vertex and occipital activity in the Attend and Ignore conditions for extraverts and introverts (left panel) and high and low Disinhibitors (right panel). Negative values indicate occipital dominance, positive values indicate vertex dominance. 


\section{DISCUSSION}

\section{Attention}

None of the two procedures used in this study corresponded precisely to the traditional augmenting-reducing paradigm, where $S$ s are left to determine the deployment of their attention on their own. For the interpretation of the results it is important to note this difference, especially since the results emphatically show that the components of interest are influenced by attention. Furthermore, differences between the two attention levels used in this study can not plausibly be reduced to differences in general arousal. The distract condition included attentive listening to a tape-recording, and adherence to the task was evaluated by questions from the experimenter after each session. Performance on both this and the flash-counting task was high throughout, and, although no quantitative assessment was made, the performance seemed to exclude the possibility that gross fluctuations of arousal had taken place. In addition, the distract condition, which resulted in lower amplitudes, was, if anything, the more demanding.

Against this background, it is interesting to note the marked difference between extraverts and introverts in their response to the attention manipulation. By all accounts, introverts seemed to display a more narrowly focussed attention, which turned more exclusively toward the flashes in the Attend condition, and toward the auditory input in the Ignore condition. This resulted in large differences in absolute amplitude (for the P200) and in amplitude-intensity function (for both N120 and P200). For extraverts, on the other hand, differences between conditions were smaller, indicating a more evenly distributed attention over the whole perceptual environment.

The difference in attention deployment between personality groups can be explained as a result of the combined influences of higher arousal in introverts, as predicted by Eysenck (1967), and narrower attention in high arousal, as predicted by Easterbrook (1959). According to the theory of Easterbrook, the range of cue utilization is progressively restricted by increases in arousal, emotionality and anxiety. The hypothesis has gained support from studies of dual-task performance, where it has been found that performance on the secondary task suffers from, and the primary task profits by, increases in state arousal. A further elaboration of this reasoning has been given by Walley and Weiden (1973), who propose a physiological mechanism of arousal-dependent lateral inhibition to account for the reduced range of stimulus cues utilized in high arousal.

In the present case, higher arousal in introverts would entail a tendency to concentrate on the task at hand, increasing amplitudes and amplitude-intensity functions of the non-specific vertex potentials when attention is directed toward the light flashes, and decreasing them when attention is directed toward the concurrent auditory task. For extraverts, lower arousal would leave a broader range of environmental stimuli accessible, thus minimizing the difference between the two attention conditions. Furthermore, it is worth noting that the attention-related personality differences only affected the secondary vertex responses, not the primary, modality specific responses recorded at $\mathrm{Oz}$.

Concerning the traditional augmenting-reducing paradigm, it is not unreasonable to assume that aversively intense flashes will induce a tendency to turn attention away from the stimuli, if instructions so permit. This tendency will be more urgently felt, and more effectively carried out, by introverts due to higher arousal. Since the tendency increases with stimulus intensity, the result will be the personality differences in augmenting/reducing documented by e.g. Lukas (1987), Stenberg et al. (1988), and Zuckerman et al. (1974). If, on the other hand, stimuli are not aversively intense, and intensities are delivered in randomized order, as in the procedure used by Haier $e t$ al. (1984), there will be no build-up of expectancies and no intensity-dependent attention strategies. Instead, instructions to watch the flashes may be more effectively complied with by introverts within an unchallenged focus of attention, producing the results found by Haier $e t$ al.

\section{Artifacts}

Concerns raised by the observations of Iacono et al on the influence of ocular artifacts were allayed by the finding that artifacts suppressed, rather than created, the personality differences in vertex responses. In a wider perspective, however, their reservations are well founded. It is almost impossible to use high-intensity visual stimuli without creating ocular artifacts. Even if blinks can be avoided, the early $(100-150 \mathrm{msec})$ myogenic artifacts, thought to originate in the orbicularis 
oculi muscles (Allison et al., 1977), and recorded to intense stimuli of all modalities, are not easily suppressed. Any artifact rejection procedure, manual or automatic, would either have to be so lax as to allow contaminated sweeps into the average, or so strict as to demand an inordinate number of sweeps to select from, which would tax the cooperation of the subjects beyond reasonable expectations. Some post-hoc compensation for artifacts, such as the one proposed by Iacono et al. or the regression approach used here, seems to be the most feasible solution.

\section{Vertex-occiput balance}

The most striking finding of this study was the pervasive difference between introverts and extraverts in the relative strength of occipital vs vertex activity. In both conditions and at all intensities, introverts had relatively stronger occipital responses, and extraverts relatively stronger vertex responses. This replicates the earlier finding by Stenberg et al. (1988). The same tendency held for the Disinhibition groups as well, although in that case modified by condition and stimulus intensity. Analogous differences have been found in some developmental studies (Cohn et al., 1985; Dustman et al., 1982), where children tended toward vertex augmenting and occipital reducing, while the reverse held for adolescents and adults. The meaning of these results can be made clearer by some comments on the neural generators of the different responses.

The vertex response is multi-modal in the sense that similar sequences of components are evoked by visual, auditory and somatosensory stimuli, although at somewhat different latencies. It is maximally recorded at the vertex or slightly anteriorly, with a symmetrical scalp distribution. Psychological states have a strong impact (Hillyard et al., 1978). All these facts have suggested that the vertex response is generated by a diffuse projection system mediating arousal and attention. However, the finding that response depression due to refractoriness occurs between modalities, but not as strongly as within modalities, suggests that both specific and non-specific generators contribute to the response (Davis, Osterhammel, Wier \& Gjerdingen, 1972).

The search for neural generators has come to concentrate on the ascending non-specific system extending from the reticular information via the thalamus to the cortex. Along this route, Velasco et al., using intracranial recordings on human patients, found several possible generators, but concluded that the scalp-recorded visual vertex response probably originates in orbitofrontal cortex (Velasco \& Velasco, 1986; Velasco, Velasco \& Olvera, 1985). Näätänen and Picton (1987) place the generator of the modality-independent N1 component more dorsally, in frontal and premotor cortex, and conclude, based on an extensive review of studies, that "this response is the cortical projection of a reticular process that facilitates motor activity" (p. 412).

Fair agreement exists that the occipital $\mathrm{P} 100$ is the result of an inhibitory process in the thalamo-recipient layers of the visual cortex (Zemon, Victor \& Ratliff, 1986). For the occipitally recorded N140, Lehtonen (1973) showed that it is not a volume-conducted replica of the vertex $\mathrm{N} 120$, since the two react differently to experimental parameters. The generator of the N140 is not clear. Allison et al., who performed topographical studies of VEPs, point out that its topography is variable, but their published maps suggest an origin in peristriate cortex, or in visual centers of the temporal lobes, both of which are areas known from PET studies to be metabolically activated by this type of stimulation (Celesia, 1986).

Assuming, then, that the occipital response is a concomitant of perceptual analysis, and the vertex response is part of an alerting reaction which includes motor preparation, the psychological significance of a disposition for one or the other becomes clearer. Brebner and Cooper (1974) have suggested, on the basis of reaction time data, that introverts are 'geared to inspect', and extraverts are 'geared to respond'. Along the same line, Stelmack and Plouffe (1983) concluded from physiological data that extraverts exhibit selective facilitation of motor processes, and introverts a corresponding facilitation of sensory processes. The findings concerning the relative strength of the vertex responses and the occipital responses in the present study are compatible with this line of reasoning. It is interesting to note that the strongest myogenic EOG activity was shown by extraverts, under conditions where they also showed the strongest vertex response. Other studies (Larsson, 1956, 1960a, b) have shown a correlation between vertex potentials and startle reflexes.

The balancing of the two types of responses may be carried out at the level of the thalamus, where the reticular nucleus is in a position to gate and modulate the output of both specific and non-specific nuclei (Scheibel, 1980). It can do this based on efferents from the frontal cortex, where 
both attention level, expectations of aversive stimulation and other response-set factors can be weighed in. Alternatively, the balancing could be effectuated by cortico-cortical associations, since the frontal lobes project back to sensory association areas, e.g. those of the visual areas in the temporal lobes, with which they are reciprocally connected (Nauta, 1971).

The contradictory results in the literature concerning auditory augmenting-reducing may be derived from the fact that the vertex response to auditory stimuli contains a summation of both specific components, generated in auditory areas of the temporal lobes, and non-specific, frontal lobe components (Näätänen \& Picton, 1987). The relative strength of each will be determined by parameters such as interstimulus interval and attention level, and studies employing different parameters are likely to get different results concerning augmenting-reducing, as indeed the record shows.

It is worth noting that for the occipital, perceptual part of the visual response studied here, the original conception of Petrie (1967) applies, according to which extraverts are reducers, i.e. disposed to attenuate the perceptual impact of stimulation. The tendency of introverts to carry out perceptual processing even in the face of aversive stimulation offers interesting resemblances to the findings of MacLeod, Mathews and Tara (1986), who showed that anxious $S$ s have a bias toward visual processing of threatening words, while non-anxious $S$ s have the opposite bias, toward innocuous stimuli. Furthermore, this tendency affects stages of processing that are seemingly not under conscious control (Mathews \& MacLeod, 1986).

Acknowledgements - This study was supported by a grant (84/215) from the Bank of Sweden Tercentenary Foundation. Technical assistance from Mrs Christina Lidbom is gratefully acknowledged.

\section{REFERENCES}

Allison, T., Matsumiya, Y. \& Goff, R. W. (1977). The scalp topography of human visual evoked potentials. Electroencephalography and Clinical Neurophysiology, 42, 185-197.

Brebner, J. \& Cooper, C. (1974). The effect of a low rate of regular signals upon the reaction time of introverts and extraverts. Journal of Research in Personality, 8, 263-276.

Buchsbaum, M. S. \& Silverman, J. (1968). Stimulus intensity control and the cortical evoked response. Psychosomatic Medicine, 30, 12-22.

Buchsbaum, M. S., Haier, R. J. \& Johnson, J. (1983). Augmenting and reducing: Individual differences in evoked potentials. In Gale A. \& Edwards J. A. (Eds), Physiological correlates of human behaviour (Vol. 3, pp. 117-138). London: Academic Press.

Celesia, G. C. (1986). Correlation between visual evoked potentials and visualization of regions of cortical activation by positron emission tomography. In Cracco, R. Q. \& Bodis-Wollner, I. (Ed.), Evoked potentials (pp. 320-330). New York: Liss.

Cohn, N. B., Dustman, R. E. \& Shearer, D. E. (1985). The effect of age, sex and interstimulus interval on augmenting and reducing of occipital VEPs. Electroencephalography and Clinical Neurophysiology, 62, 177-183.

Cumo, P. G., Simons, R. \& Zuckerman, M. (1984). Psychophysiological indices of sensation seeking as a function of stimulus intensity. Psychophysiology, 21, 572-573.

Connolly, J. F, and Gruzelier, J. H. (1982). Amplitude and latency changes in the visual evoked potential to different stimulus intensities. Psychophysiology, 19, 599-608.

Connolly, J. F. \& Kleinman, K. M. (1978). A single channel method for recording vertical and lateral eye movements. Electroencephalography and Clinical Neurophysiology, 45, 128-129.

Davis, H., Osterhammel, P.A., Wier, C. C. \& Gjerdingen, D. B. (1972). Slow vertex potentials: Interactions among auditory, tactile, electric and visual stimuli. Electroencephalography and Clinical Neurophysiology, 33, 537-545.

Dustman, R. E., Shearer, D. E. \& Snyder, E. W. (1982). Age differences in augmenting/reducing of occipital visually evoked potentials. Electroencephalography and Clinical Neurophysiology, 54, 99-110.

Easterbrook, J. A. (1959). The effect of emotion on cue utilization and the organisation of behaviour. Psychological Review', $66,183-201$.

Eysenck, H. J. (1967). The biological basis of personality. Springfield, Ill.: Thomas.

Eysenck, H. J. \& Eysenck, S. B. G. (1969). Personality structure and measurement. London: Routledge.

Friedman, J. \& Meares, R. (1979). Cortical evoked potentials and extraversion. Psychosomatic Medicine, 41, $279-286$.

Haier, R. J., Robinson, D. L., Braden, W. \& Williams, D. (1984). Evoked potential augmenting-reducing and personality differences. Personality and Individual Differences, 5, 293-301.

Hall, R. A., Rappaport, M., Hopkins, H. K., Griffin, R. \& Silverman, J. (1970). Evoked response and behavior in cats. Science, $170,998-1000$.

Hegerl, U., Prochno, I., Ulrich, G. \& Müller-Oelinghausen, B. (1989). Sensation seeking and auditory evoked potentials, Biological Psychiatry, 25, 179-190.

Hillyard, S. A., Picton, T. W. \& Regan, D. (1978). Senation, perception and attention: Analysis using ERPs. In Callaway, E., Tueting, P. \& Koslow, S. H. (Ed.), Event-related brain potentials in man (pp. 223-321). New York: Academic Press.

Iacono, W. G., Gabbay, F. H. \& Lykken, D. T. (1982). Measuring the average evoked response to light flashes: The contribution of eye blink artifact to augmenting-reducing. Biological Psychiatry. 17, 897-911. 
Kaskey, G. B., Salzman, L. F., Klorman, R. \& Pass, H. L. (1980). Relationships between stimulus intensity and amplitude of visual and auditory event related potentials. Biological Psychology, 10, 115-125.

von Knorring, L. (1980). Visual averaged evoked responses and platelet monoamine oxidase in patients suffering from alcoholism. In Begleiter, H. (Ed.), Biological effects of alcohol (pp. 649-660). New York: Plenum Press.

Larsson, L. E. (1956). The relation between the startle reaction and the non-specific EEG response to sudden stimuli with a discussion on the mechanism of arousal. Electroencephalography and Clinical Neurophysiology, 8, 631-644.

Larsson, L. E. (1960a). Correlation between the psychological significance of stimuli and the magnitude of the startle blink and evoked EEG potentials in man. Acta Physiologica Scandinavica, 48, 276-294.

Larsson, L. E. (1960b). Sensitization of the startle blink and non-specific electrocephalographic response. Electroencephalography and Clinical Neurophysiology, 12, 727-733.

Lehtonen, J. B. (1973). Functional differentiation between late components of visual evoked potentials recorded at occiput and vertex: Effect of stimulus interval and contour. Electroencephalography and Clinical Neurophysiologv, 35, 75-82.

Lukas, J. H. (1987). Visual evoked potential augmenting-reducing and personality: The vertex augmenter is a sensation seeker. Personality and Individual Differences, 8, 385-395.

Lukas, J. H. \& Siegel, J. (1977). Cortical mechanisms that augment or reduce evoked potentials in cats. Science, $198.73-75$.

MacLeod, C. Mathews, A. \& Tara, P. (1986). Attention bias in emotional disorders. Journal of Abnormal Psychology, 95, $15-20$.

Mathews, A. \& MacLeod, C. (1986). Discrimination of threat cues without awareness in anxiety states. Journal of Abnormal Psychology, 95, 131-138.

Mullins, L. F. \& Lukas, J. H. (1984). Auditory augmenters are sensation seekers--if they attend the stimuli. Psychophysiology, 21, 589 .

Näätänen, R. \& Picton, T. (1987). The N1 wave of the human electric and magnetic response to sound: A review and an analysis of the component structure. Psychophysiology, 24, 375-425.

Nauta, W. (1971). The problem of the frontal lobe: A reinterpretation. Journal of Psychiatric Research 8, 167-187.

Orlebeke, J. F., Kok, A. \& Zeillemaker, C. W. (1989). Disinhibition and the processing of auditory stimulus intensity: An ERP study. Personality and Individual Differences. 10, 445-451.

Petrie, A. (1967). Individuality in pain and suffering. Chicago: University of Chicago Press.

Raine, A., Mitchell, D. A. \& Venables, P. (1981). Cortical augmenting-reducing-modality specific? Psychophysiology, 18, 700-707.

Saxton, P. M., Siegel, J. \& Lukas, J. H. (1987). Visual evoked potential augmenting/reducing slopes in cats-2. Correlations with behavior. Personality and Individual Differences, 8, 511-519.

Schechter, G. \& Buchsbaum, M. (1973). The effects of attention, stimulus intensity and individual differences on the averaged evoked response. Psychophysiology, 10, 392-400.

Scheibel, A. B. (1980). Anatomical and physiological substrates of arousal: a view from the bridge. In Hobson, J. A. \& Brazier, M. A. B. (Ed.), The reticular formation revisited. New York: Raven Press.

Soskis, D. A. \& Shagass, C. (1974). Evoked potential tests of augmenting-reducing. Psychophysiology, 11, $175-190$.

Stelmack, R. M. \& Plouffe, L. (1983). Introversion-Extraversion: The Bell-Magendie law revisited. Personality and Individual Differences, 4, 421-427.

Stenberg, G., Rosén, I. \& Risberg, J. (1988). Personality and augmenting/reducing in visual and auditory evoked potentials. Personality and Individual Differences, 9, 571-579.

Vasey, M. W. \& Thayer, J. F. (1987). The continuing problem of false positives in repeated measures ANOVA in psychophysiology: A multivariate solution. Psychophysiology, 24, 479-486.

Velasco, M. \& Velasco, A. (1986). Subcortical correlates of the somatic auditory and visual vertex activities. II. Referential EEG responses. Electroencephalography and Clinical Neurophysiology, 63, 62-67.

Velasco, M., Velasco, R. \& Olvera, A. (1985). Subcortical correlates of the somatic, auditory and visual vertex activities in Man. I. Bipolar EEG responses and electrical stimulation. Electroencephalography and Clinical Neurophysiology, 61, 519-529.

Walley, R. E. \& Weiden, T. D. (1973). Lateral inhibition and cognitive masking: A neuropsychological theory of attention. Psychological Review, 80, 284-302.

Zemon, V. D., Victor, J. D. \& Ratlif,, F. (1986). Functional subsystems in the visual pathways of humans characterized using evoked potentials. In Cracco, R. Q. \& Bodis-Wollner, I. (Ed.). Evoked potentials. New York: Liss.

Zuckerman, M. (1979). Sensation seeking: Beyond the optimal level of arousal. Hillsdale, N. J: Erlbaum.

Zuckerman, M., Murtaugh, T. \& Siegel, J. (1974). Sensation seeking and cortical augmenting-reducing. Psychophysiology, $11,535-542$. 